\title{
Acquiring an understanding of design: evidence from children's insight problem solving
}

\author{
Margaret Anne Defeyter ${ }^{\mathrm{a}}$, Tim P. German ${ }^{\mathrm{b}, *}$ \\ ${ }^{a}$ Department of Psychology, University of Essex, Colchester, UK \\ ${ }^{\mathrm{b}}$ Department of Psychology, University of California, Santa Barbara, CA 93106-9660, USA
}

Received 12 October 2002; revised 7 January 2003; accepted 16 April 2003

\begin{abstract}
The human ability to make tools and use them to solve problems may not be zoologically unique, but it is certainly extraordinary. Yet little is known about the conceptual machinery that makes humans so competent at making and using tools. Do adults and children have concepts specialized for understanding human-made artifacts? If so, are these concepts deployed in attempts to solve novel problems? Here we present new data, derived from problem-solving experiments, which support the following. (i) The structure of the child's concept of artifact function changes profoundly between ages 5 and 7 . At age 5, the child's conceptual machinery defines the function of an artifact as any goal a user might have; by age 7 , its function is defined by the artifact's typical or intended use. (ii) This conceptual shift has a striking effect on problem-solving performance, i.e. the child's concept of artifact function appears to be deployed in problem solving. (iii) This effect on problem solving is not caused by differences in the amount of knowledge that children have about the typical use of a particular tool; it is mediated by the structure of the child's artifact concept (which organizes and deploys the child's knowledge). In two studies, children between 5 and 7 years of age were matched for their knowledge of what a particular artifact "is for", and then given a problem that can only be solved if that tool is used for an atypical purpose. All children performed well in a baseline condition. But when they were primed by a demonstration of the artifact's typical function, 5-yearold children solved the problem much faster than 6-7-year-old children. Because all children knew what the tools were for, differences in knowledge alone cannot explain the results. We argue that the older children were slower to solve the problem when the typical function was primed because (i) their artifact concept plays a role in problem solving, and (ii) intended purpose is central to their concept of artifact function, but not to that of the younger children.
\end{abstract}

(C) 2003 Elsevier Science B.V. All rights reserved.

Keywords: Artifacts; Function; Design; Insight; Tool use; Problem solving; Cognitive development

\footnotetext{
* Corresponding author. Fax: +1-805-893-4303.

E-mail address: german@psych.ucsb.edu (T.P. German). 


\section{Introduction}

Using tools to solve novel problems is one of the paradigmatic human cognitive capacities (Pinker, 2002), although it does not distinguish us qualitatively from other animals: 'tool use' has been documented in the wild in a number of primates (Hauser, 1997; Tomasello \& Call, 1997) and, probably most strikingly, recently in the laboratory in the New Caledonian crow (Weir, Chappell, \& Kacelnik, 2002). Nevertheless, the wide variety, complexity and technological sophistication of human tools and artifacts surely make humans the 'ultimate tool users'. A brief tally of the relative numbers of artifacts versus natural objects in one's immediate environment will likely provide a rapid sense of exactly how pervasive human-made artifacts are (Tomasello, 1999).

Despite our being a tool-using species, the cognitive capacities underlying the acquisition of knowledge about artifacts are not well understood, nor are the capacities that allow us to transfer efficiently this knowledge in solving simple novel problems. Although psychological research on these topics began around 70 years ago (e.g. Matheson, 1931; Richardson, 1932), there has been a striking lack of research devoted to understanding the cognitive basis of tool use and its development in humans (see e.g. Want \& Harris, 2001) - especially when compared with the efforts devoted to characterizing and understanding tool use and its development in species that succeed only sporadically, such as capuchins and crows.

Most studies investigating the knowledge that adults and children have about artifacts have focused on intuitions about objects and their functions in categorization tasks, function judgment tasks and word extension tasks (e.g. Gentner, 1978; German \& Johnson, 2002; Hall, 1995; Kelemen, 1999; Kemler Nelson, 1999; Landau, Smith, \& Jones, 1998; Matan, 1995; Matan \& Carey, 2001; Rips, 1989). But such tasks may fail to reveal important aspects of artifact knowledge - aspects relevant to problem solving. Indeed, one could argue that 'core' conceptual systems (e.g. agency, Leslie, 1994; object mechanics, Spelke, Breinlinger, Macomber, \& Jacobson, 1992; and number, Wynn, 1998) ought to promote action and problem solution, not just the mere contemplation of knowledge for its own sake (see e.g. Cosmides \& Tooby, 1994; Hood, Carey, \& Prasada, 2000). Herein, we explore the possibility that the conceptual systems that organize knowledge about artifacts do affect human choice and action. More specifically, we investigate the possibility that they play a role in the human capacity to choose tools appropriate for solving novel problems.

\subsection{Representing artifact function via the 'design stance'}

Adult reasoning about artifacts appears to reflect the adoption of the 'design stance' (Dennett, 1987), an abstract explanatory schema that captures the relationship between features of an entity (e.g. its material, shape and activities) in terms of a coherent organizing notion - the purpose for which its designer created it. Categorization tasks show that adults tend to judge an object's category on the basis of (i) its intended function rather than its appearance (Rips, 1989), and (ii) its designed function rather than its current use (Hall, 1995; Kelemen, 1999; Matan \& Carey, 2001). Moreover, adults also judge an 
object's function on the basis of the original intentions of the designer over other intentional uses and accidental activities (German \& Johnson, 2002; Kelemen, 1999).

But what are the developmental origins of the design stance? Recent research and evidence in cognitive development has suggested that developing commonsense understanding of the world is based on what Cosmides and Tooby (2001) call systems of 'dedicated intelligence' - rapid learning guided by specialized domains of core knowledge, which allow perception of, attention to, and reasoning about important classes of entities in the children's environment (such as number, object mechanics and agency; see also Spelke, 2000). According to this framework, one possible route by which humans understand artifacts is via mechanisms dedicated to just this process - inference systems that have been selected to represent the category of tools and underlie the capacity for tool use - what Pinker (2002) calls 'intuitive engineering' (see also Boyer, 2001).

An alternative possibility for the representation and learning of artifact concepts (albeit also consistent with the core knowledge framework) is the idea that knowledge of artifact function reflects an understanding 'improvised' by combining different domains of 'core knowledge'. First, artifact function representation can be argued to require the capacity to represent and reason about the physical properties of an object and the constraints that those physical properties place on its motion and possible interactions with other objects (e.g. an object's 'affordances'; Gibson, 1979; Vaina, 1983). Second, because objects can be similar enough in shape and structure to afford exactly the same activities (e.g. an ashtray and a soup bowl), artifact function is also constrained by information about the social agents who create and use those objects to fulfill their goals - information provided by an intuitive psychology (German \& Defeyter, 2000; German \& Johnson, 2002; Kelemen, 1999).

Under the view that artifact representation might be based on consideration of an object's mechanical structure and the goals of agents using that artifact, the notion of 'design' is assumed to emerge and plays a central role in organizing artifact knowledge only later in development (German \& Johnson, 2002). While some theorists argue that understanding of design guides reasoning about object functions from about age 4 or even earlier (Kelemen, 1999; Kemler Nelson, 1999; Kemler Nelson, Herron, \& Morris, 2002; Kemler Nelson, Russell, Duke, \& Jones, 2000), a consensus of evidence derived from a number of tasks suggests the shift occurs somewhat later, around 6 years of age (Gentner, 1978; German \& Johnson, 2002; Graham, Williams, \& Huber, 1999; Landau et al., 1998; Matan, 1995; Matan \& Carey, 2001). ${ }^{1}$

\subsection{Problem solving and the representation of artifact function}

As noted at the outset, a puzzling gap in the literature on children's conceptual representations of artifacts concerns the deployment of those representations in solving problems that require the use of simple tools. Though the development of means-end problem solving has been studied (Brown, 1990; Sobel, 1939; van Leeuwen, Smitsman, \&

\footnotetext{
${ }^{1}$ A full treatment of this disagreement is beyond the scope of the present paper, and in fact the contradiction is not as significant as might first appear. The interested reader is referred to the discussion in German and Johnson (2002).
} 
van Leeuwen, 1994), this research had not been linked explicitly to the conceptual representation of artifacts. This link was made explicit by German and Defeyter (2000), who studied the impact of artifact concepts on children's performance on a class of objectuse problems made popular by the Gestalt school of psychology (e.g. Duncker, 1945; Maier, 1931). In these tasks, the subject needs to solve a problem using a particular object of known function (variously, a box, a paperclip, a screwdriver, etc.). However, to solve the problem, the tool must be used in an unusual way. For example, in the 'candle problem' (see also Adamson, 1952), subjects are presented with a candle, a book of matches and a box of tacks, and asked to fix the candle to a vertical screen. To solve the problem, the tack box must be used as a platform. Adults are far more likely to arrive at this solution - indeed, to find it obvious - when the box is presented without the tacks inside than when the box is presented full of tacks. In other words, priming the box's typical function - containment - makes it more difficult to see that the problem can be solved by using the box in an atypical manner. This phenomenon is called functional fixedness.

Traditional interpretations of functional fixedness propose that accumulated knowledge about the object's regular design function is activated by the demonstration of that function, and this somehow blocks alternative uses which otherwise would come easily to mind, creating an 'impasse' (Knoblich, Ohlsson, \& Raney, 2001). Both the 'mental ruts' hypothesis, which suggests that repeated exploration of knowledge elements in the unsuccessful search for solutions activates incorrect pathways, causing the impasse (Smith, 1995), and the 'representational change' hypothesis, which proposes that the initial representation of the problem interacts with prior knowledge in a way that activates knowledge elements that are not helpful in solving the problem (e.g. Kaplan \& Simon, 1990; Knoblich et al., 2001), are rooted in this assumption that past knowledge is key to understanding object use when people solve insight problems.

The assumption of the importance of past knowledge is nowhere more pronounced than in discussions of children's learning. In the words of Brown (1989): “one of the more ubiquitous claims concerning young children is that they tend to acquire knowledge in such a way that it is closely tied, restricted or welded to habitual occasions of use" (p. 369). But in explaining functional fixedness in both adults and children, German and Defeyter (2000) have proposed an alternative to explanations based on accumulated experience alone: the emerging design stance hypothesis. On this view, knowledge of a tool's typical function can cause functional fixedness only in solvers whose concept of artifact function embodies the 'design stance'. The idea is that each individual has an abstract concept of artifact function, and that this concept plays a role in problem solving, organizing knowledge about a tool's possible functions. The hypothesis that functional fixedness is caused by the nature of an abstract concept of artifact function might be difficult to test with adults, given the prevalence of the design stance in adult populations (at least in Europe and America). But it can be tested in children by comparing problem solving by 6- and 7-year-olds - who do reason in accordance with the design stance - to that of 5-year-olds, who appear to lack the relevant design concepts.

German and Defeyter (2000) reasoned that if younger children's representation of artifact function is not based around design, but rather improvised on the basis of representations of an object's mechanical properties on the one hand, and representations 
of the goals of agents on the other, then an interesting, counterintuitive prediction follows: younger children might be less susceptible than older children to functional fixedness. German and Defeyter (2000) presented 5-, 6- and 7-year-old children with a task analogous to the candle problem. The children's task was to help a puppet reach a high shelf, and the solution was to use a box as a platform (rather than as a container), in order to raise a tower of bricks to the required height. In the key function demonstration condition (i.e. when function was primed), the box was presented in use for its typical function: containment. The bricks and several other inappropriate items (e.g. a coin, pencil eraser, toy car) were presented inside the box. In the baseline condition (function not primed), the box and other items were presented separately. The results showed the following:

(i) In the baseline condition, the problem was trivially easy for all the children. This demonstrated that, seen merely as a means-end problem, the task was simple.

(ii) Like adults in the candle problem, 6- and 7-year-olds showed evidence of functional fixedness: they were slower in reaching the solution when the box's typical function was primed than when it was not.

(iii) In marked contrast, the 5-year-olds showed no evidence of functional fixedness: they solved the problem just as fast when the box's typical function was primed as when it was not. Moreover, the 5-year-olds actually were faster than both 6- and 7-yearold groups in solving the problem when the containment function of the box was first demonstrated.

German and Defeyter (2000) argued that the emergence of fixedness in the older children was not caused by increasing knowledge about the habitual function of specific familiar objects per se, but rather to changes in the way that children reason about artifacts in general - changes in the structure of their artifact concepts. Not only is this supported by prior research suggesting that concepts of artifact function do indeed undergo a shift between age 5 and ages 6-7 (German \& Johnson, 2002; Matan, 1995; Matan \& Carey, 2001), but it is also consistent with the body of literature showing that by age 5 - and indeed, even earlier - children already have abundant knowledge about everyday object functions (e.g. Abravanel \& Gingold, 1985; Gauvain \& Greene, 1994; McDonough \& Mandler, 1998). This makes it unlikely that the 5-year-olds' lack of functional fixedness was caused by a straightforward lack of knowledge about the typical function of a box. ${ }^{2}$

Nevertheless, it is still possible that because older and younger children may differ in the extent of their accumulated experience with the habitual functions of familiar objects, older children fail to overcome this 'force of habit' when attempting to generate an alternative to the function of containment during the box task of German and Defeyter (2000). Because this initial functional fixedness study was carried out using objects with familiar known functions, as has most often been the case in tool use problem-solving tasks conducted with young children (e.g. objects such as hooks and rakes; Brown, 1989; Sobel, 1939) and indeed invariably in functional fixedness tasks with adult participants too

\footnotetext{
2 Indeed, Defeyter and German (2000) also showed that children show the same basic pattern of performance on the 'box' task if they are first required to demonstrate the standard function of the box.
} 
(Birch \& Rabinowitz, 1951; Divesta \& Walls, 1967; Duncker, 1945; Flavell, Cooper, \& Loiselle, 1958; Glucksberg \& Weisberg, 1966; Yonge, 1966), the precise nature of the interaction between accumulated past knowledge, conceptual structure and problem presentation remains unclear. Remarkably, despite the importance of the idea that 'negative transfer of past knowledge' contributes to functional fixedness, there have been no systematic attempts to manipulate the knowledge about object function that participants bring to a functional fixedness problem.

Scholars in cognitive development regularly meet this kind of empirical challenge via the use of arbitrary, novel stimuli such that "children are equated for knowledge by their lack of it" (Brown, 1989, p. 385). In the present case, the use of novel objects in a functional fixedness problem offers widely different predictions on the basis of the 'accumulated knowledge of habitual use' versus the 'emerging design stance' hypotheses. If children's increasing susceptibility to functional fixedness arises through habitual use of objects for their typical functions, then no such fixedness should result for problems where the objects and functions used are novel. On the other hand, the emerging design stance hypothesis predicts the opposite. Children's emerging sensitivity to 'design' in the way their artifact concepts are represented should result in older children interpreting the novel information about the object's function as a core property of the object, just as for familiar artifacts. The priming of the canonical function will then block the generation of alternative uses in the novel object problem too.

There were two aims in the current research. In Experiment 1, the counterintuitive findings of German and Defeyter (2000) were replicated, in an improved object use insight problem with familiar objects. In the second study, the key predictions outlined above were tested in a task involving novel objects matched in terms of mechanical properties ('affordances') to the familiar objects of Experiment 1.

\section{Experiment 1}

A new functional fixedness task was designed in which the task was to free an object from a Perspex tube using a suitably long tool to push the object from the middle to one end and then out. This task was based on one used by Bíró (2001).

Children were presented with this problem under one of two conditions. Children in the function demonstration condition were presented with a total of six objects. Two of these objects had their conventional functions demonstrated, in each case making use of another object (e.g. a pencil and straw had their functions demonstrated using a pad of paper and a cup of water). The final two objects were presented without comment (a plastic ruler and a yellow ping pong ball). Of the two pre-utilized objects, only one could be used to solve the task (e.g. the pencil was long enough to reach the object and thin enough to fit inside the tube) - the other was inappropriate (e.g. the straw was thin enough but too short). Neither of the two demonstration objects (the pad of paper or the cup) would solve the problem, and neither would the distracter objects (the ruler was too wide to fit in the tube and the ball too short). Two objects were pre-utilized to guard against the possibility that drawing attention to one object only would create a pragmatic bias toward (or against) the later use of that object. Children in the baseline condition were presented with the same six objects, 
but these were all introduced without comment. In addition, the objects were placed such that their conventional functions were not demonstrated merely by context (e.g. the straw was placed away from the cup, not inside or next to it).

We measured fixedness in two ways. First, we recorded the first item selected for use in the problem. Second, we measured the latency to select the target item and begin to use it in a solution attempt, irrespective of in which order it was eventually selected. ${ }^{3}$

\subsection{Method}

\subsubsection{Participants}

One hundred and twenty children participated. They were recruited from primary schools in and around Colchester, Essex, UK, serving a variety of social backgrounds. All participants had English as a first language and none of the children tested had any identified learning difficulty. The children were randomly assigned to either the function demonstration condition or the baseline condition. In the function demonstration condition there were 20 5-year-olds ( 9 boys, 11 girls, mean age 5-2, range 4-11 to 5-6), 20 6-yearolds (13 boys, 7 girls, mean age 6-0, range 5-8 to 6-3) and 20 7-year-olds (11 boys, 9 girls, mean age 6-11, range 6-8 to 7-3). In the baseline condition there were 205 -year-olds (11 boys, 9 girls, mean age 5-0, range 4-9 to 5-5), 20 6-year-olds (11 boys, 9 girls, mean age 6-0, range 5-8 to 6-4) and 20 7-year-olds (11 boys, 9 girls, mean age 7-1, range 6-11 to 7-4).

\subsubsection{Task and materials}

The materials consisted of a transparent plastic tube $(28.5 \mathrm{~cm}$ long $\times 4.55 \mathrm{~cm}$ internal diameter), a ruler $(18 \mathrm{~cm}$ long $\times 4.8 \mathrm{~cm}$ wide $)$, a translucent table tennis ball $(3.9 \mathrm{~cm}$ diameter), a clear plastic cup $(6.5 \mathrm{~cm}$ high $\times 7.0 \mathrm{~cm}$ diameter $)$, a pencil and paper holder $(14.2 \mathrm{~cm}$ wide $\times 20 \mathrm{~cm}$ long), and a pad of $3 \mathrm{M}$ 'Post-it Notes' $(12.7 \mathrm{~cm}$ long $\times 7.7 \mathrm{~cm}$ wide). There was also a short $(9.2 \mathrm{~cm})$ pencil and a long pencil $(19 \mathrm{~cm})$ and a short straw $(9.2 \mathrm{~cm})$ and a long straw $(19 \mathrm{~cm})$. A soft toy pet measuring $12.2 \mathrm{~cm}$ long was folded up so that it only measured $9 \mathrm{~cm}$ long and was lodged in the middle of the transparent plastic tube. A further doll measuring $16 \mathrm{~cm}$ high was used as the story character.

\subsubsection{Procedure}

Children were seated opposite the experimenter at a low table in a quiet area of their classroom. They were introduced to the protagonist puppet, and told: "This is Sam. He's going on a long journey in his spaceship, and he's collected together some things for his trip." The object set was then placed on the table in front of the children as follows.

\subsubsection{Function demonstration condition. The two objects to be pre-utilized were always}

\footnotetext{
3 These measures of fixedness have two advantages over the 'solution time' measure used by German and Defeyter (2000). First, solution time can obviously be computed only for solvers, and this might result in small sample sizes (as in German \& Defeyter's study). Second, even for those who solve, the overall solution time is subject to influence by many factors, such as the skill with which the children execute the task once the object has been selected. These factors are not strictly relevant to whether the child shows evidence of being fixed on a preutilized object, because one child might solve the problem quickly by trying each object and rejecting it until the correct object was found, while another child might be slower, yet have selected the appropriate object first.
} 
introduced first, each with their associated object for the demonstration. For half the children, the pencil and pad were introduced first, and the function of the pencil was demonstrated by writing Sam's name on the pad: "These are things Sam uses for writing. Here is how Sam writes his name." The word 'SAM' was written on the pad, and the object was placed in the holder on the pad. These objects were followed for these children by the straw and cup, and the function of the straw was then demonstrated: "These are things that Sam uses for drinking. Here is how Sam takes a drink." A small amount of water was sucked through the straw by the Experimenter, and the straw was left upright in the cup. The other half of the children received these demonstrations in the reverse order. In addition, the object (straw or pencil) that was the target solution object was also counterbalanced across children, so that for half the children, the pencil was the target object for the task (i.e. it was the long pencil) while the straw was the pre-utilized distracter (i.e. it was the short straw), while for the other half the opposite configuration was used. After the objects and functions were introduced, two control questions were asked to ensure that the children had registered the familiar functions. For example, the pencil and straw were held up in turn and children were asked: "Can you tell me what this is for?" To be scored correct, children were required to repeat back the function that had been introduced immediately before (e.g. "for writing" and "for drinking", respectively).

With the objects in place, the children were introduced to the problem. The Perspex tube, with the toy animal lodged inside, was shown to the children. They were told: "Sam has a pet called Tog. Naughty Tog has run away and got stuck in this tube. Sam can't leave until Tog is free. Can you show Sam how he can get Tog out of the tube? You can use any of Sam's things, but you can only use one at a time." The tube was then placed on the table in front of the child. Fig. 1A shows the set-up of the materials as faced by the child in this condition. The trial began when the object was placed on the table in front of the child, and ended when the child had freed the toy animal from the tube.

After the solution had been reached, two further control questions were asked about the functions of the pre-utilized objects. Children were shown the objects in turn, in the order in which they had originally been presented, and asked: "Can you remember what this is for?" Again, children were scored correct if they were able to identify the function of the object that had been introduced before the problem.

2.1.3.2. Baseline condition. In the baseline condition the objects were introduced under the same counterbalancing constraints as described above. However, there were additional constraints placed on the object's positions, such that the pairs of objects used in the function demonstration condition to demonstrate functions were kept apart. Hence, when the pencil and pad were the first items introduced, as above, they were placed apart on the table so that in the final configuration they were separated by at least one other object. This procedure was adopted for the straw and cup also. Finally, the distracter objects were placed in between the pairs of related objects. This was to ensure that children were less likely to represent the object's function on the basis of the context. After the objects had been placed, the problem was presented as in the function demonstration condition. The set-up of task and materials as faced by the child in this condition is shown in Fig. 1B. As for the function demonstration condition, the trial began with the placement of the problem on the table in front of the child, and ended when the toy had been freed from the tube. 
A.
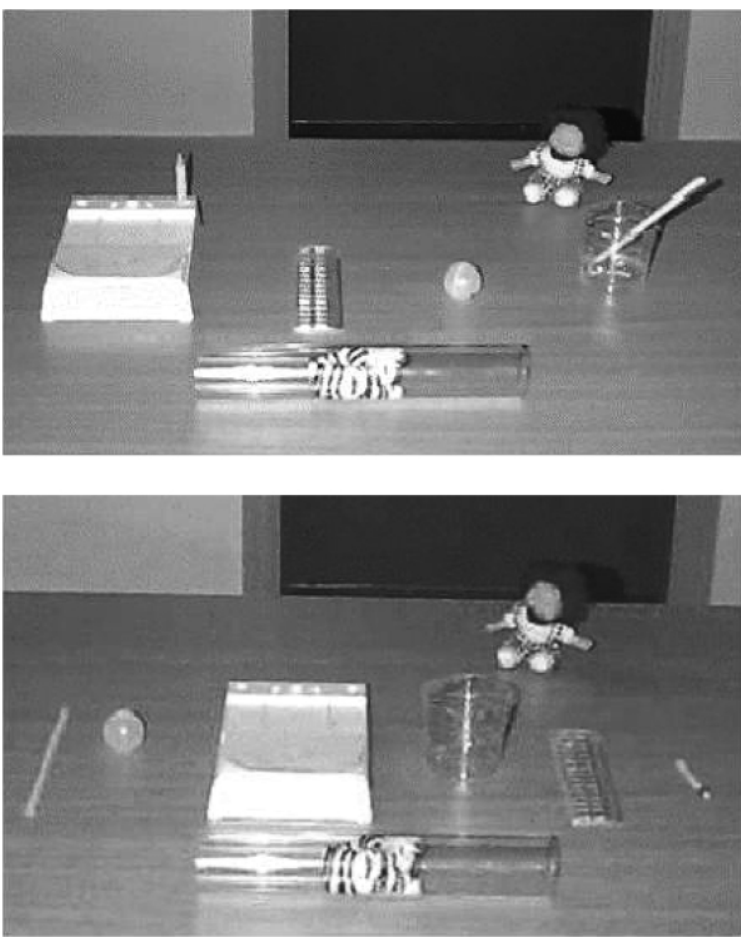

Fig. 1. Experimental set-up after presentation of objects in the function demonstration condition (A) and the baseline condition (B) in Experiment 1.

\subsection{Results and discussion}

All children answered the first pair of control questions accurately. There were no cases where a child did not repeat the function of either object that had been introduced moments earlier. There were also no differences in how detailed or elaborate children's responses were; older and younger children's answers were indistinguishable on these questions.

Participants were scored from the videotaped sessions according to whether or not the first object they selected for use in the problem was the target object (e.g. the functional object). The latency from the time when the experimenter finished presenting the problem until the target object was selected and used in a solution attempt was also recorded. ${ }^{4}$ Preliminary analyses confirmed that there were no overall effects on either of these dependent variables of the solution set (e.g. whether the target object was the straw or the pencil) or the order in which the target item was introduced (first or second). These factors were therefore collapsed for all further analyses.

The percentage of participants, at each age group and in each condition, selecting the target object first is presented in Table 1. These results indicate evidence of fixedness

${ }^{4}$ Defined as the target object being placed so as to come into contact with the opening of the tube. 
Table 1

Percentage of children selecting the target object for the first solution attempt according to age and condition in Experiment 1

\begin{tabular}{llll}
\hline & 5-year-olds & 6-year-olds & 7-year-olds \\
\hline Function demonstration & $60 \%$ & $40 \%$ & $40 \%$ \\
Baseline & $80 \%$ & $80 \%$ & $95 \%$
\end{tabular}

among both the 6- and 7-year-old children, with children in the function demonstration condition in both age groups less likely to select the target object first $\left(\chi_{N=40, \text { d.f. }=1}^{2}=6.7\right.$, $P<0.01$, two-tailed; $\chi_{N=40, \text { d.f. }=1}^{2}=13.8, P<0.001$, two-tailed, for 6 - and 7-year-old groups, respectively). The difference between function demonstration and baseline conditions in the 5-year-old group fell short of significance $\left[\chi_{N=40, \text { d.f. }=1}^{2}=1.9\right.$, NS $]$. Despite a slight tendency for younger children to be more likely to select the target object first $(60 \%)$ than the older two groups $(40 \%)$, there were no reliable effects of age in either condition $\left(\chi_{N=60, \text { d.f. }=2}^{2}=2.14\right.$, NS, for function demonstration; $\chi_{N=60 \text {, d.f. }=2}^{2}=2.39$, NS, for baseline).

The median latency to select the target object according to age and condition appears in Fig. 2. This graph presents a picture consistent with that which emerged from consideration of the first object preferences, with both older groups tending to show marked functional fixedness, while the younger group showed none. These impressions were confirmed by Mann-Whitney $U$-tests on the latencies to select the target object ( $U=95, U=75, P s<0.01$, for 6- and 7-year-olds, respectively; $U=178, \mathrm{NS}$, for the

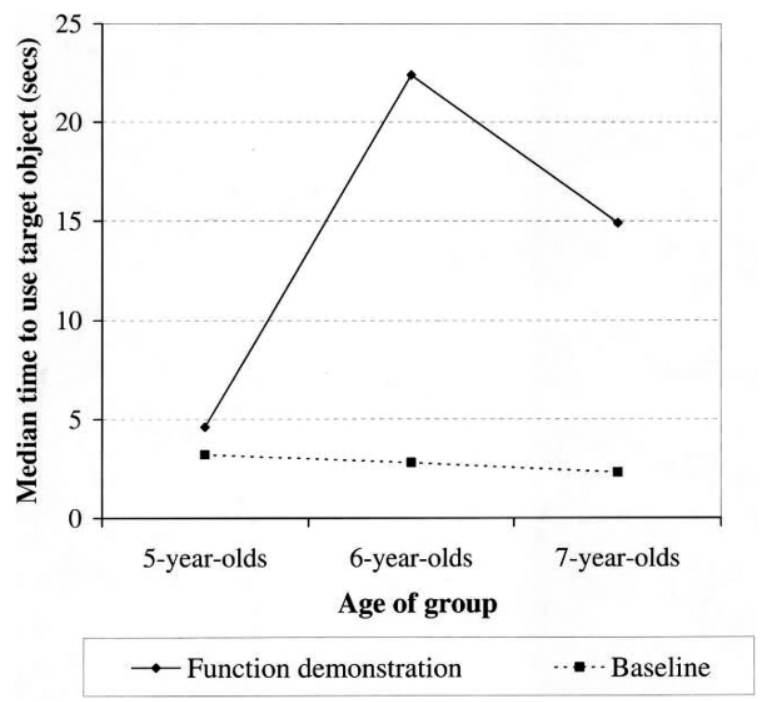

Fig. 2. Median time to select the target object (seconds) according to age in function demonstration and baseline conditions of Experiment 1. 
5-year-old group). Analysis of the effect of age within each condition, via KruskalWallace tests, revealed a significant difference between groups for the function demonstration condition $\left(H_{(2)}=7.06, P<0.029\right)$, but none in the no pre-utilization condition $\left(H_{(2)}=13.14\right.$, NS). Post-hoc analysis revealed that the mean rank difference between the 5- and 6-year-old groups only was significant, with 5-year-olds significantly faster to select the target item than the 6-year-olds, but not quite significantly faster than the 7-year-olds.

Finally, the children performed extremely well on the second pair of control questions. All but two children answered with the functions identified by the experimenter. One young child and one old child deviated from this pattern, saying that the pencil was "for drawing", rather than for writing. Other than that the responses were all versions of the described functions, and the older and younger children's responses did not differ in detail nor in precision.

These results replicate, in essence, the finding of German and Defeyter (2000) of 'immunity' to functional fixedness in 5-year-old children, in a new task with additional controls. The second experiment presented here provides the key test of the two competing hypotheses about the emergence of functional fixedness outlined in Section 1. Though functional fixedness has typically been characterized as the result of transfer of specific knowledge about habitual object function interfering in problem solving (e.g. Brown, 1989; Duncker, 1945; Flavell et al., 1958; Keane, 1989) there has been no assessment of the interaction between the content or structure of prior knowledge about artifact function and fixedness in problem solving. Here, by presenting tasks with novel objects with newly taught functions, we control the prior acquired knowledge of object function.

To recap, if functional fixedness can be demonstrated to show the same developmental pattern as in Experiment 1, then accounts of functional fixedness in terms of specific accumulated knowledge of habitual object functions will be undermined. This result would instead provide further support for the idea that functional fixedness is a consequence of the general emergence of an understanding of artifacts in terms of design (German \& Defeyter, 2000; German \& Johnson, 2002).

\section{Experiment 2}

\subsection{Method}

\subsubsection{Participants}

One hundred and twenty children participated. They were recruited from primary schools in and around Colchester, Essex, UK, serving a variety of social backgrounds. All participants had English as a first language and none had taken part in Experiment 1. The children were randomly assigned to either the function demonstration condition or the baseline condition. In the function demonstration condition there were 205 -year-olds (11 boys, 9 girls, mean age 5-1, range 4-10 to 5-5), 20 6-year-olds (9 boys, 11 girls, mean age 6-2, range 5-8 to 6-4) and 20 7-year-olds (10 boys, 10 girls, mean age 7-0, range 6-8 to $7-4)$. In the baseline condition there were 20 5-year-olds ( 10 boys, 10 girls, mean age 5-0, 
range 4-9 to 5-5), 20 6-year-olds (11 boys, 9 girls, mean age 6-1, range 5-8 to 6-3) and 20 7-year-olds (9 boys, 11 girls, mean age 7-1, range 6-9 to 7-5).

\subsubsection{Task and materials}

The materials consisted of the same transparent plastic tube $(28.5 \mathrm{~cm}$ long $\times 4.55 \mathrm{~cm}$ internal diameter) used in Experiment 1, a piece of hard plastic cut into an ' $S$ ' shape $(25.5 \mathrm{~cm}$ long $\times 4.3 \mathrm{~cm}$ wide $)$, a purple table tennis ball $(3.9 \mathrm{~cm}$ diameter $)$ mounted on a plastic bottle cap $(3 \mathrm{~cm}$ wide $\times 1.5 \mathrm{~cm}$ high), and a glass holder $(9.5 \mathrm{~cm}$ high $\times 6.3 \mathrm{~cm}$ diameter) with red, yellow and green LEDs inserted into the glass. There was also a clear Perspex stick (19 cm long) with a magnet drilled into each end and a short Perspex stick $(9.2 \mathrm{~cm})$ with a small magnet drilled into each end. The glass holder was mounted onto a black plastic base $(5 \mathrm{~cm}$ high $\times 6.8 \mathrm{~cm}$ diameter) containing a power supply (battery). On the top of the black base there were five magnetic switches connected to the LEDs. This equipment was designed in such a way so that when one of the sticks with magnetic ends was placed into the glass holder the LEDs lit up. There was also a gray plastic box $(7.5 \mathrm{~cm}$ wide $\times 4.5 \mathrm{~cm}$ high). The plastic box had four holes $(5 \mathrm{~mm})$ drilled into the top surface under which four buzzers were positioned. There was also a long white plastic stick $(19 \mathrm{~cm})$ and a short white plastic stick $(9.2 \mathrm{~cm})$. This equipment was designed so that when one of the white sticks was pushed into one of the holes on top of the gray box a high tone was heard. The soft toy and doll were the same as used in Experiment 1 (the toy was lodged in the tube as before).

\subsubsection{Procedure}

Children were seated opposite the experimenter at a low table in a quiet area of their classroom. They were introduced to the protagonist puppet and told: "This is Zig. He's going on a long journey in his spaceship, and he's collected together some things for his trip." The problem set objects were then placed on the table in front of the children.

3.1.3.1. Function demonstration condition. The two objects to be pre-utilized were always brought out first, each with their associated object for the demonstration. Half the children were presented with the magnetic rod and light cup first (the 'light stick'), and the function of the rod was demonstrated. The magnetic rod was placed into the cup, lighting up the lights on the cup's surface. Children were told: “These are things Zig uses for making light. Here is how Zig makes light." These children were then shown the plastic prod and music box object pair (the 'music stick'), and the function of the prod was demonstrated: "These are things that Zig uses to make music. Here is how Zig makes music." The remaining half of the children received these demonstrations in the reverse order. Also, the object that would solve the task was counterbalanced across children, such that for half the children, the target object for the task was the light stick (which was presented in its long version) while the music stick was the pre-utilized distracter (i.e. was presented in its short version). The other half of the children received the opposite configuration of objects. After the function demonstrations children were asked a pair of control questions to ensure that they remembered the functions of the objects. Children were scored correct on these questions if they were able to identify the function that had been introduced for each object. These were asked for each of the two pre-utilized objects, in the order that 
they had been introduced. For example, the children were shown the magnetic Perspex rod and asked: "Can you remember what this is for?" Children were scored correct if they answered that it was "for making light".

Following this, the two other distracter objects were then brought out together: "Here are some other things that Zig is taking on his journey." The distracter objects were both placed in random positions between the two pre-utilized object pairs.

With the objects in place, the children were introduced to the problem. The Perspex tube, with the toy animal lodged inside, was shown to the children. They were told: "Zig has a pet called Tog. Naughty Tog has run away and got stuck in this tube. Zig can't leave until Tog is free. Can you show Zig how he can get Tog out of the tube? You can use any of Zig's things, but you can only use one at a time." The tube was then placed on the table in front of the child. Fig. 3A shows an example of the set-up of the materials as faced by a child faced with this condition. The trial began when the object was placed on the table in front of the child, and ended when the child had freed the toy animal from the tube.

3.1.3.2. Baseline condition. In the baseline condition the objects were introduced under the same counterbalancing constraints as described above. As in Experiment 1, the pairs of objects used in the function demonstration condition to demonstrate functions were kept
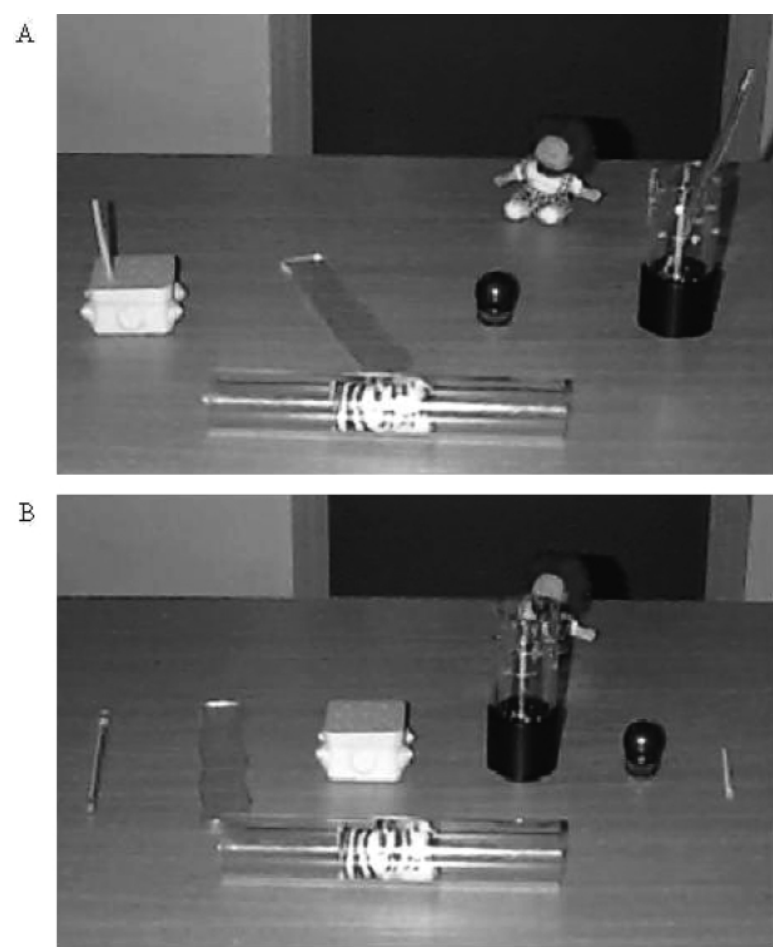

Fig. 3. Experimental set-up after presentation of objects in the function demonstration condition (A) and the baseline condition (B) in Experiment 2. 
apart. After the objects had been placed, the problem was presented as in the function demonstration condition. The set-up of task and materials as faced by the child in this condition is shown in Fig. 3B. As for the function demonstration condition, the trial began with the placement of the problem on the table in front of the child, and ended when the toy had been freed from the tube.

\subsection{Results and discussion}

There were no failures to respond correctly to the first pair of control questions. All the children answered these questions by reporting that the Perspex magnetic rod was "for making light", or "to light the cup" and that the plastic stick was "for making music". There were no differences between the groups of children in the detail of their responses for either answer. Most children answered simply with "making light" and "making music", and the answers of the older and younger children were indistinguishable on this measure.

Children were scored from the videotaped sessions according to whether or not the first object they selected for use in the problem was the target object (e.g. the functional object). The latency from the time when the experimenter finished presenting the problem until the target object was selected and used in a solution attempt was also recorded. Once again, preliminary analyses revealed no overall effects of the item set ('light stick' solution or 'music stick' solution) or the order in which the target object had been introduced (first or second) on either of these two dependent variables.

Table 2 shows the overall frequency with which children in each age group, and in each condition, selected the target object as their first choice for a solution attempt. This table shows a similar pattern of results as that found in Experiment 1. There was strong evidence of functional fixedness in both older groups of children, as marked by a strong tendency to avoid selecting the target object under conditions where its function had been demonstrated as compared with conditions where it had not $\left(\chi_{N=40 \text {, d.f. }=1}^{2}=15.82\right.$, $P<0.001$, two-tailed for 6-year-olds; $\chi_{N=40, \text { d.f. }=1}^{2}=6.67, P<0.01$, two-tailed for 7 -year-olds). However, there was again no evidence of functional fixedness in the younger group $\left(\chi_{N=40, \text { d.f. }=1}^{2}=0, \mathrm{NS}\right)$. Moreover, and unlike in Experiment 1 , the children in the youngest group were significantly more likely to select the target object first than either of the older groups (for 5- versus 6-year-olds, $\chi_{N=40, \text { d.f. }=1}^{2}=6.46, P<0.05$, two-tailed; for 5- versus 7-year-olds, $\chi_{N=40, \text { d.f. }=1}^{2}=5.01, P<0.05$, two-tailed).

The median latency to select the target object for use in a solution attempt, according to age and condition, appears in Fig. 4. Analysis of these results confirmed that there was

Table 2

Percentage of children selecting the target object for the first solution attempt according to age and condition in Experiment 2

\begin{tabular}{llll}
\hline & 5-year-olds & 6-year-olds & 7-year-olds \\
\hline Function demonstration & $75 \%$ & $35 \%$ & $40 \%$ \\
Baseline & $75 \%$ & $95 \%$ & $80 \%$ \\
\hline
\end{tabular}




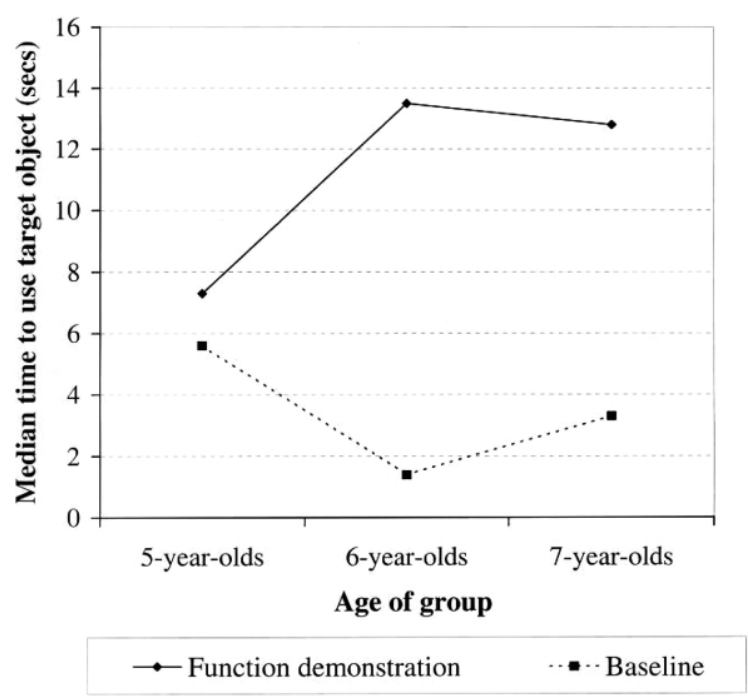

Fig. 4. Median time to select the target object (seconds) according to age in function demonstration and baseline conditions of Experiment 2.

evidence for functional fixedness in both the 6- and the 7-year-old groups. Both groups were slower to select the target object when its function had been demonstrated than when they had no such demonstration $(U=51, P<0.001 ; U=96, P<0.05$ for 6 - and 7-yearolds, respectively). By contrast, there was no evidence of functional fixedness in the 5 -year-old group, who were as quick to select the target object in either condition $(U=179.5$, NS). Finally, Kruskal-Wallace tests revealed an effect of age in the baseline condition only $\left(H_{(2)}=12.58, P<0.05\right)$, which post-hoc analysis of the mean ranks in each group revealed to result from the 5-year-old group being slower than both the 6- and 7-year-old groups.

The demonstration, in 6- and 7-year-olds, that functional fixedness can be induced in a problem-solving task with novel objects and newly taught functions is inconsistent with the proposal that functional fixedness emerges merely as a result of the accumulation of real world knowledge about objects. All the children in the function demonstration condition of this experiment had the same experience with the objects and their functions, yet were affected very differently when it came to setting aside their knowledge and using the objects for an alternative purpose. The fact that fixedness was demonstrated in the 6- and 7-year-old groups in the novel object study is strong evidence in favor of the idea that children move from a flexible notion of function based on attending to agents and their goal based object use at 5 years of age (German \& Johnson, 2002) to a notion of function based on including the idea of 'original design' at about age 6 (Matan \& Carey, 2001).

Finally, and again in line with the first experiment, there was no evidence from the control questions inquiring about the functions of the objects before or after the problem that the older children were describing the functions in an any more elaborate or detailed 
way. At a descriptive level therefore, there was again no evidence that the processing of the described functions by older children was 'deeper' than that by the younger children. ${ }^{5}$

\section{General discussion}

The interaction between existing knowledge and the representation of a novel problem is important to theories of insight problem solving (Knoblich et al., 2001; Luchins \& Luchins, 1959; Smith, 1995). Nevertheless, there have been very few attempts to measure or control the content or structure of the knowledge about test objects that participants bring to the task. Instead, researchers have tended to employ familiar artifacts (so that knowledge of canonical function can be assumed) and focused efforts on manipulating the amount, variety or order of the experiences that solvers are presented with during testing, or immediately before (e.g. Birch \& Rabinowitz, 1951; Divesta \& Walls, 1967; Flavell et al., 1958; Glucksberg \& Danks, 1968; Glucksberg \& Weisberg, 1966; Yonge, 1966).

A similar focus on the use of familiar actions with familiar objects can be identified in the developmental literature on simple tool use problem solving (e.g. pulling or pushing via rakes, hooks, sticks, etc.; Brown, 1989, 1990; Matheson, 1931; Richardson, 1932; Sobel, 1939; van Leeuwen et al., 1994; Want \& Harris, 2001). Indeed, Brown (1989) argues that focusing on simple causal relations (such as pushing, pulling) that children well understand may be critical for transfer of knowledge to new situations to be achieved. However, as noted in Section 1, a weakness of this approach is that it requires one to make assumptions about the conceptual machinery and extent of knowledge that the participant brings to the problem. The results of Experiment 2 show that in a task where older and younger children were equated for their experience with a set of artifacts and associated functions, via the employment of novel artifacts with novel functions, the older children still experienced more problems in generating an alternative use for an object if its design function had been recently demonstrated.

By contrast, younger children were as quick to select the target object for use in a tool use problem whether the design function had been demonstrated or not. Moreover, the younger children were more likely than the older children to select the target object during the first solution attempt under conditions where its design function had been demonstrated. 'Functional fixedness' has typically been assumed to be caused by extensive past experience with objects and their habitual functions (e.g. Duncker, 1945; Flavell et al., 1958; Keane, 1989) and inappropriate transfer of extensive knowledge has been implicated more broadly in theories of 'insight' (e.g. Knoblich et al., 2001; Luchins

\footnotetext{
${ }^{5} \mathrm{We}$ are grateful to an anonymous reviewer for bringing to our attention the relevance for these results of a 'depth of processing' framework. Whether differences in depth of processing of function between older and younger children are a useful way to characterize these results has much to do with how 'deep' versus 'shallow' processing is to be cashed out in terms of the mechanisms in the child's developing cognitive system. Though we find no evidence for more elaborate processing of information about function in older children's answers to the control questions, artifact processing might indeed be 'deeper' in older children via their having access to the abstract explanatory design stance schema. Our proposal is therefore not an alternative to an account conceived in terms of depth of processing, but rather can be construed as a proposal for a mechanism by which 'deeper' processing might be supported in this domain.
} 
\& Luchins, 1959; Smith, 1995). The current results suggest that, at least in the case of object based insight problems, extensive experience with habitual functions of the objects is not necessary for functional fixedness to occur.

These results can be incorporated into a developing set of findings derived from research into the acquisition of understanding about artifacts and design (e.g. German \& Defeyter, 2000; German \& Johnson, 2002; Matan \& Carey, 2001). This view proposes that while adults think about artifacts via an explanatory framework that places emphasis on the artifact's designed purpose - the 'design stance' - children must construct this understanding from a number of more basic reasoning systems (including object mechanics and commonsense psychology). A number of converging lines of evidence suggest that knowledge of artifact concepts in terms of design occurs at about 6 years of age (Gentner, 1978; German \& Defeyter, 2000; German \& Johnson, 2002; Graham et al., 1999; Landau et al., 1998; Matan, 1995; Matan \& Carey, 2001; Smith, Jones, \& Landau, 1996).

On this view, functional fixedness is created in older children because their conception of the novel artifact is organized around a core property - its 'design' - and this core property is primed by the demonstration of function during the presentation of the problem, blocking the availability of other functions. By contrast, younger children process the information presented about the object's function not as a core property, but as just one possible goal for which the object can serve, given its structure. The fact that fixedness emerges in children even when the objects involved are novel (Experiment 2) fits into this framework, consistent with evidence that something general about the conception of artifacts is changing at about age 6 .

One challenge to this view is that some studies find a weak preference for understanding design in 4-5-year-old children (Kelemen, 1999, 2001). Kelemen also found no evidence that the emergence of an understanding of design correlated with measures of functional fixedness (Kelemen, 2001). This result can be considered a failure to replicate the results of German and Defeyter (2000), and to contrast with those presented here. One way that the contradictory results can be reconciled would be to argue that the understanding of design demonstrated in younger children in Kelemen's tasks is fragile - the preference for original function over current function in the 'many intentional' condition of her study was somewhat weak (63\%), consistent with the weak evidence of understanding design shown in one of Matan and Carey's studies (Matan \& Carey, 2001, Experiment 3). It is therefore possible that an earlier emerging understanding of design, though demonstrable when conditions are favorable, is simply not robust enough to support functional fixedness until later in development. ${ }^{6}$

There is further converging evidence for the idea of a flexible notion of object function in younger children, giving way to an understanding of artifacts organized around their design (Defeyter \& German, 2001). Using a simple task in which participants are required to generate as many novel functions for everyday objects (e.g. a brick, a blanket) as possible in a set time, it was shown that 5-year-old and 7-year-old children produce very

\footnotetext{
6 A further consideration is that Kelemen (2001) also showed that while the understanding of design is weak in 4-year-olds, it is absent in 3-year-olds. This suggests that the developmental pattern is consistent, even if the precise ages are in dispute.
} 
different patterns of responses. Seven-year-olds tend to produce first the standard function of the object (e.g. "to build a house" in the case of a brick; "to cover the bed" in the case of blanket) and subsequently produce variations on this standard function (e.g. in the case of a brick: "build a wall, build a school, build a castle", etc.). Five-year-olds also tended to produce the design function for the object, but their further answers were less likely to be variations on this designed function, and more likely to be other plausible uses for the object (e.g. "to stop a door from blowing closed in the wind" for a brick; "use [the blanket] as a tent", etc.). Overall, 5-year-olds produced more novel functions than the 7-year-olds, while 7-year-olds produced more variations on the design function than the 5-year-olds (Defeyter \& German, 2001). This pattern of results suggests that 7-year-olds organize their search for novel functions for an artifact by generating extensions of its core designed function, while 5-year-olds, though they know about and can generate the design function, do not constrain their search for new answers around the design function in the same way as do 7-year-olds.

A final line of evidence suggests that the organization of adult semantic memory appears to reflect the same distinction between information about an object's design function and information representing the wider goals it can perform, which we hypothesize here distinguishes younger and older children's psychology of artifact representation. This evidence comes from cases of semantic dementia, where there is progressive loss of conceptual knowledge as a result of temporal lobe atrophy (Hodges, Patterson, Oxbury, \& Funnell, 1992; Warrington, 1975). This impairment is specific to the conceptual system; there is good associated performance in such individuals on day-to-day memory, short-term memory, verbal reasoning, and other domain-general cognitive capacities. Critically, however, semantic dementia patients have been found who lose knowledge about the canonical design functions of familiar objects (e.g. they fail to answer questions such as "What is this spoon for?"), suggesting that function is no longer represented as a core property of their artifact concept. Interestingly, these patients nevertheless retain the ability to solve problems requiring an understanding of the goals which particular novel objects can be used to perform (e.g. the combination of mechanical affordances and goals tested by asking: "Which object can lift the weight?"; Hodges, Bozeat, Ralph, Patterson, \& Spatt, 2000; Hodges, Spatt, \& Patterson, 1999). Though other explanations are possible, one way of characterizing this pattern of impairment is in terms of these adults being forced to rely on core knowledge systems (object mechanics, intuitive psychology) to reason about object function. On this view, they are reasoning via the same conceptual apparatus deployed by children of 5 years and younger, who are yet to construct the design stance. ${ }^{7}$

If indeed children begin to construct the design stance at about age 6 , but show at best only weak evidence of having done so before this age, as proposed here, then one reasonable question concerns what drives this developmental change. The key element of the design stance that appears to be absent in the young child is the idea that what

\footnotetext{
${ }^{7}$ Interestingly, there is also one reported case in which information about an object's current use was preserved in the face of loss of knowledge of design function - a case of a woman with semantic dementia who was unable to report the canonical function of a jug (e.g. to pour milk, water), and instead reported her own current use of that object (e.g. to hold flowers; Snowden, Griffiths, \& Neary, 1994).
} 
something is 'intentionally made for' outweighs other factors (what its mechanical properties 'afford', what it looks like, what it is currently being used for, etc.) when explaining its nature. Two facts strike us as suggesting that the notion of 'made for' might be late acquired.

First, it is the case that information about the original intentions relevant at the time an object was created may be relatively inaccessible, even to adults. The creation of most objects will be a matter of historical fact, and historical information is surely less easily attended to and processed. Instances where a child gets direct information about 'intentions of a creator' are likely to be few and far between, certainly relative to instances where children witness an object being used to fulfill a goal. Hence, children may have little evidence about intentional creation events from which to glean the importance of this information. Fortunately, considering current goals will almost invariably result in a judgment of object function that is consistent with the design function, since agents invariably use objects for their designed functions.

Secondly, we suggest that understanding the notion of 'made for' is more complex, in representational terms, than understanding a simple goal-directed object use. One way of characterizing design is as a second order recursive mental state. The idea is that understanding 'intentionally made for purpose $x$ ' involves coordinating two concurrent mental states; that of the maker, and that of a subsequent user (e.g. as in "INVENTOR intends that USER wants that..."). On this analysis, any weakness processing secondorder mental states might limit one's ability to parse the complex mental state 'intentionally made for' into its components. If the maker's intention (to create the object) cannot be segregated from the final goal (the purpose for which the object is to be used) then the child will not be able to even attend to both aspects of the event. By hypothesis, the eventual goal of the user 'overshadows' the goal of the creator, and the information about the 'making event' will therefore be glossed as a regular goal, equivalent to other goals associated with the object. Once the dual nature of the 'made for' mental representation can be segregated, the privileged status of the designer's goal compared to other goals can be attended to, and can be entered as the core property of the entity. ${ }^{8}$

There is evidence that reasoning about recursive mental states is far more difficult for children than reasoning about first order mental states. While proficient reasoning about agents' goals has been shown from late infancy (see e.g. Gergely, Nadasdy, Csibra, \& Bíró, 1995; Spelke, Phillips, \& Woodward, 1995), the ability to deploy an early competence with mental states is known to be affected by various performance factors which continue to develop over the period between 4 and 7 years of age (German \& Leslie, 2000, 2001; Leslie \& Polizzi, 1998). Critically, reasoning about recursive mental state contents is known to lag behind reasoning about first order mental states (Perner \& Wimmer, 1985; Sullivan, Winner, \& Hopfield, 1995). Preschool and young school age children, on this view, can begin to attend to the importance of design only as their

\footnotetext{
${ }^{8}$ Note that the claim here is that the difficulty with the notion of intentional design arises because first order metal states are more easily processed than second order metal states, not because children below the age of 6 cannot attribute recursive mental states. There is in fact evidence that they can, under circumstances when processing demands are reduced (e.g. Sullivan, Zaitchik, \& Tager-Flusberg, 1994).
} 
developing brains begin routinely to handle the rich processing demands of recursive mental states such as 'made/designed for' at around age 6-7 years (for further discussion see German \& Johnson, 2002).

In summary, the studies reported here add to the accumulating evidence for changes in the nature of children's understanding of artifacts and their functions in the late preschool or early school years. We argue that an initial understanding of artifacts derived from combining information about the goals of agents and the mechanical properties of objects, an understanding improvised from the output of 'core knowledge' systems dedicated to reasoning about agents and objects respectively, gives way to artifact concepts that are structured around a core property of 'design'. This development appears to bring with it a number of phenomena, including robust categorization via information about original design (Matan \& Carey, 2001), intuitions and explanations about object function sensitive to design (German \& Johnson, 2002), extension of the designed function as a strategy for generating multiple functions (Defeyter \& German, 2001) and the emergence of functional fixedness (German \& Defeyter, 2000).

At the same time, the studies reported herein indicate that the concept of artifact function plays an important role in problem solving. Differences in the extent of accumulated knowledge or experience about artifact function cannot explain the differences in functional fixedness between the younger and older children. The children in both experiments had knowledge of the function of the tools in question, and in Experiment 2 the children also had equivalent inexperience with the objects' functions. By hypothesis, the only difference between them was the nature of their artifact concept. The results are best explained as resulting from this difference in conceptual structure. Knowledge of a tool's function is not irrelevant, but the role it plays depends on the underlying concept of function, which organizes the child's knowledge and deploys it when the child is called upon to choose a tool to solve a problem. Functional fixedness, according to this general framework, can be viewed as a costly side effect of a conceptual system designed to promote efficient problem solution when tools are used for typical functions.

\section{Acknowledgements}

This research was supported by the Economic and Social Research Council of the UK (grant \#R00429934065), and conducted in partial fulfillment of the requirements for the degree of $\mathrm{PhD}$, awarded to M.D. We are grateful to the staff, children and parents of Broomgrove Infants, Montgomery Infants, Monkwick Infants, Hazelmere Infants and St Andrews Infant Schools for agreeing to help with the studies reported here. We would also like to thank Roger Deeble for creating the materials used in Experiment 2, Szilvia Bíró, Deb Kelemen, James Russell and Karen Wynn for helpful discussion of the issues raised here and Steve Avons, Gyorgy Gergely, Leda Cosmides, Cristina Sorrentino, and two anonymous reviewers for helpful comments on an earlier draft of this manuscript. 


\section{References}

Abravanel, E., \& Gingold, H. (1985). Learning via observation during the second year of life. Developmental Psychology, 21, 614-623.

Adamson, R. E. (1952). Functional fixedness as related to problem solving: a repetition of three experiments. Journal of Experimental Psychology, 44, 288-291.

Birch, H. G., \& Rabinowitz, H. S. (1951). The negative effect of previous experience on productive thinking. Journal of Experimental Psychology, 41, 121-125.

Bíró, S (2001). The role of the arbitrariness of actions in autistic executive dysfunction. Unpublished PhD thesis, Department of Psychology, University of Cambridge.

Boyer, P. (2001). Religion explained. New York: Basic Books.

Brown, A. L. (1989). Analogical learning and transfer: what develops? In S. Vosniadou, \& A. Ortony (Eds.), Similarity and analogical reasoning (pp. 369-412). New York: Cambridge University Press.

Brown, A. L. (1990). Domain-specific principles affect learning and transfer in children. Cognitive Science, 14, $107-133$.

Cosmides, L., \& Tooby, J. (1994). Origins of domain specificity: the evolution of functional organization. In L. A. Hirschfeld, \& S. A. Gelman (Eds.), Mapping the mind: domain specificity in cognition and culture (pp. 85-116). New York: Cambridge University Press.

Cosmides, L., \& Tooby, J. (2001). Unravelling the enigma of human intelligence: evolutionary psychology and the multi-modular mind. In R. J. Sternberg, \& J. C. Kaufman (Eds.), The evolution of intelligence (pp. 145-198). Mahwah, NJ: Lawrence Erlbaum Associates.

Defeyter, M. A., \& German, T. P (2000, September). Characterizing the emergence of functional fixedness: flexible or impoverished representations of artifact function? Paper presented at the British Psychological Society, Cognitive Section, University of Essex, Colchester.

Defeyter, M. A., \& German, T (2001, April). Functional fluency: measuring young children's intuitions about object functions. Paper presented at the Society for Research in Child Development, Minneapolis, MN. Manuscript in preparation.

Dennett, D. C. (1987). The intentional stance. Cambridge, MA: MIT Press.

Divesta, F. J., \& Walls, R. T. (1967). Transfer of object-function in problem solving. American Educational Research Journal, 4, 207-216.

Duncker, K. (1945). On problem-solving. Psychological Monographs, 58(ix), 113.

Flavell, J. H., Cooper, A., \& Loiselle, R. H. (1958). Effect of the number of pre-utilization functions on functional fixedness in problem solving. Psychological Reports, 4, 343-350.

Gauvain, M., \& Greene, J. K. (1994). What do young children know about objects? Cognitive Development, 9 , 311-329.

Gentner, D. (1978). A study of early word meaning using artificial objects: what looks like a jiggy but acts like a zimbo? Papers and Reports on Child Language Development, 15, 1-6.

Gergely, G., Nadasdy, Z., Csibra, G., \& Bíró, S. (1995). Taking the intentional stance at 12 months of age. Cognition, 56, 165-193.

German, T. P., \& Defeyter, M. A. (2000). Immunity to functional fixedness in young children. Psychonomic Bulletin \& Review, 7, 707-712.

German, T. P., \& Johnson, S. (2002). Function and the origins of the design stance. Journal of Cognition \& Development, 3, 279-300.

German, T. P., \& Leslie, A. M. (2000). Attending to and learning about mental states. In P. Mitchell, \& K. J. Riggs (Eds.), Children's reasoning and the mind (pp. 229-252). Hove: Psychology Press/Taylor \& Francis.

German, T. P., \& Leslie, A. M. (2001). Children's inferences from 'knowing' to 'pretending' and 'believing'. British Journal of Developmental Psychology, 19, 59-83.

Gibson, J. J. (1979). The ecological approach to vision. Boston, MA: Houghton Mifflin.

Glucksberg, S. A. M., \& Danks, J. H. (1968). Effects of discriminative labels and of nonsense labels upon availability of novel function. Journal of Verbal Learning \& Verbal Behavior, 7, 72-76.

Glucksberg, S., \& Weisberg, R. W. (1966). Verbal behavior and problem solving: some effects of labeling in a functional fixedness problem. Journal of Experimental Psychology, 71, 659-664. 
Graham, S. A., Williams, L. D., \& Huber, J. F. (1999). Preschoolers' and adults' reliance on object shape and object function for lexical extension. Journal of Experimental Child Psychology, 74, 128-151.

Hall, D. G (1995). Artifacts and origins. Unpublished manuscript, University of British Columbia, Vancouver.

Hauser, M. D. (1997). Artifactual kinds and functional design features: what a primate understands without language. Cognition, 64, 285-308.

Hodges, J. R., Bozeat, S., Ralph, M. A. L., Patterson, K., \& Spatt, J. (2000). The role of conceptual knowledge in object use: evidence from semantic dementia. Brain, 123, 1913-1925.

Hodges, J. R., Patterson, K., Oxbury, S., \& Funnell, E. (1992). Semantic dementia: progressive fluent aphasia with temporal lobe atrophy. Brain, 115, 1783-1806.

Hodges, J. R., Spatt, J., \& Patterson, K. (1999). "What" and "how": evidence for the dissociation of object knowledge and mechanical problem solving skills in the human brain. Proceedings of the National Academy of Sciences USA, 96, 9444-9448.

Hood, B., Carey, S., \& Prasada, S. (2000). Predicting the outcomes of physical events: two-year-olds fail to reveal knowledge of solidity and support. Child Development, 71, 1540-1554.

Kaplan, C. A., \& Simon, H. A. (1990). In search of insight. Cognitive Psychology, 22, 374-419.

Keane, M. (1989). Modelling problem solving in Gestalt "insight" problems. Irish Journal of Psychology, 10, 201-215.

Kelemen, D. (1999). The scope of teleological thinking in preschool children. Cognition, 70, 241-272.

Kelemen, D (2001, April). Intention in children's understanding of artifact function. Paper presented at the Society for Research in Child Development, Minneapolis, MN.

Kemler Nelson, D. G. (1999). Attention to functional properties in toddlers' naming and problem-solving. Cognitive Development, 14, 77-100.

Kemler Nelson, D. G., Herron, L., \& Morris, C. (2002). How children and adults name broken objects: inferences and reasoning about design intentions in the categorization of artifacts. Journal of Cognition \& Development, $3,301-332$.

Kemler Nelson, D. G., Russell, R., Duke, N., \& Jones, K. (2000). Two-year-olds will name artifacts by their functions. Child Development, 71, 1271-1288.

Knoblich, G., Ohlsson, S., \& Raney, G. E. (2001). An eye movement study of insight problem solving. Memory \& Cognition, 29, 1000-1009.

Landau, B., Smith, L., \& Jones, S. (1998). Object shape, object function, and object name. Journal of Memory \& Language, 38, 1-27.

Leslie, A. M. (1994). ToMM, ToBy, and agency: core architecture and domain specificity. In L. A. Hirschfeld, \& S. A. Gelman (Eds.), Mapping the mind: domain specificity in cognition and culture (pp. 119-148). New York: Cambridge University Press.

Leslie, A. M., \& Polizzi, P. (1998). Inhibitory processing in the false belief task: two conjectures. Developmental Science, 1, 247-253.

Luchins, A. S., \& Luchins, E. H. (1959). Rigidity of behavior: a variational approach to the effect of Einstellung. Eugene, OR: University of Oregon Press.

Maier, N. R. F. (1931). Reasoning in humans. II. The solution of a problem and its appearance in consciousness. Journal of Comparative Psychology, 12, 181-194.

Matan, A (1995, April). What are vacuum cleaners for? Paper presented at the Society for Research in Child Development, Indianapolis, IN.

Matan, A., \& Carey, S. (2001). Developmental changes within the core of artifact concepts. Cognition, 78, 1-26.

Matheson, E. (1931). A study of problem solving behavior in pre-school children. Child Development, 2, $242-262$.

McDonough, L., \& Mandler, J. M. (1998). Inductive generalization in 9- and 11-month-olds. Developmental Science, 1, 227-232.

Perner, J., \& Wimmer, H. (1985). "John thinks that Mary thinks that...”: Attribution of second-order beliefs by 5to 10-year-old children. Journal of Experimental Child Psychology, 39, 437-471.

Pinker, S. (2002). The blank slate: the modern denial of human nature. New York: Viking.

Richardson, H. M. (1932). The growth of adaptive behavior in infants: an experimental study at seven age levels. Genetic Psychology Monographs, 12, 195-359. 
Rips, L. J. (1989). Similarity, typicality, and categorization. In S. Vosniadou, \& A. Ortony (Eds.), Similarity and analogical reasoning (pp. 21-59). New York: Cambridge University Press.

Smith, L. B., Jones, S. S., \& Landau, B. (1996). Naming in young children: a dumb attentional mechanism? Cognition, 60, 143-171.

Smith, S. M. (1995). Getting into and out of mental ruts: a theory of fixation, incubation, and insight. In R. J. Sternberg, \& J. E. Davidson (Eds.), The nature of insight (pp. 229-251). Cambridge, MA: MIT Press.

Snowden, J., Griffiths, H., \& Neary, D. (1994). Semantic dementia: autobiographical contributions to preservation of meaning. Cognitive Neuropsychology, 11, 265-288.

Sobel, B. (1939). A study of the development of insight in pre-school children. Journal of Genetic Psychology, $55,381-388$.

Spelke, E. S. (2000). Core knowledge. American Psychologist, 55, 1233-1243.

Spelke, E. S., Breinlinger, K., Macomber, J., \& Jacobson, K. (1992). Origins of knowledge. Psychological Review, 99, 605-632.

Spelke, E. S., Phillips, A., \& Woodward, A. L. (1995). Infants' knowledge of object motion and human action. In D. Sperber, D. Premack, \& A. Premack (Eds.), Causal cognition: a multidisciplinary debate (pp. 44-78). New York: Clarendon Press/Oxford University Press.

Sullivan, K., Winner, E., \& Hopfield, N. (1995). How children tell a lie from a joke: the role of second-order mental state attributions. British Journal of Developmental Psychology, 13, 191-204.

Sullivan, K., Zaitchik, D., \& Tager-Flusberg, H. (1994). Preschoolers can attribute second-order beliefs. Developmental Psychology, 30, 395-402.

Tomasello, M. (1999). The cultural ecology of young children's interactions with objects and artifacts. In E. Winograd, R. Fivush, \& W. Hirst (Eds.), Ecological approaches to cognition: essays in honor of Ulric Neisser (pp. 153-170). Mahwah, NJ: Lawrence Erlbaum Associates.

Tomasello, M., \& Call, J. (1997). Primate cognition. New York: Oxford University Press.

Vaina, L. (1983). From shapes and movements to objects and actions. Synthese, 54, 3-36.

van Leeuwen, L., Smitsman, A., \& van Leeuwen, C. (1994). Affordances, perceptual complexity, and the development of tool use. Journal of Experimental Psychology: Human Perception \& Performance, 20, 174-191.

Want, S. C., \& Harris, P. L. (2001). Learning from other people's mistakes: causal understanding in learning to use a tool. Child Development, 72, 431-443.

Warrington, E. K. (1975). The selective impairment of semantic memory. Quarterly Journal of Experimental Psychology, 27, 635-657.

Weir, A. A. S., Chappell, J., \& Kacelnik, A. (2002). Shaping of hooks in New Caledonian crows. Science, 297, 981.

Wynn, K. (1998). An evolved capacity for number. In D. C. Cummins, \& C. Allen (Eds.), The evolution of mind (pp. 107-126). New York: Oxford University Press.

Yonge, G. D. (1966). Structure of experience and functional fixedness. Journal of Educational Psychology, 57, $115-120$. 